\title{
A ecologia mística de um yogi insone
}

João José Borges. Juazeiro-BA: SABEH, 2017.

"Sempre que a natureza é convidada de honra para dançar com o Espírito, uma ecologia mística se faz pulsar".

(João José Borges)

Edilane Ferreira da Silva ${ }^{1}$

Na introdução de Ecologia mística, obra lançada em novembro de 2017, o yogi e professor Dr. em Ciências Sociais, João José Borges determina: "Pois que nasça, livro a ser lido por meus pares. Que estes não me cobrem acadêmicos rigores: o inverno, aqui, é azul. E estamos cansados de distantes e neutros esforços intelectuais" (BORGES, 2017, p. 17-18). Ele faz essa afirmativa após esclarecer que a obra em questão diz respeito a um canto em três vozes, expressas na introdução, mas percorrendo todo o trabalho, a saber: uma que desempenha um exercício etnográfico, referente a uma etnografia de si mesmo; outra cujo tom é teórico, transitando, interdisciplinarmente, pela sociologia, pela filosofia e pela antropologia; e uma última, que expõe ensinamentos práticos da vivência do autor, com yoga e meditação. Ao esclarecer tal polifonia e ao tecer uma crítica à ciência moderna, que bifurca sujeito e objeto, Borges se isenta de qualquer questionamento referente à conceitualização da ecologia mística alinhada a uma pretensa imparcialidade científica, ao passo que assume um lugar de fala: o dos que defendem - e praticam - uma ciência que se irmana com a poesia da linguagem, do divino transcendental, do mundo e do ser.

A ecologia mística que o autor se propõe a abordar, portanto, vai se constituindo a partir do arsenal de teóricos/as que caracterizam a sua memória de leitura; e, especialmente, com base na sua experiência com o yoga. João José Borges é professor do curso de Jornalismo em Multimeios da Universidade do Estado da Bahia (UNEB), onde desenvolve um projeto de pesquisa e extensão, financiado pela Fundação de Amparo à Pesquisa do Estado da Bahia (FAPESB) até 2015, e, atualmente, pela própria universidade, denominado Corpoética: yoga como atividade educomunicativa nas

\footnotetext{
${ }^{1}$ Doutoranda no Programa de Estudos Literários, na Universidade Federal de Alagoas (UFAL). É, também, integrante do Grupo Mare\&Sal Estudos e Pesquisas Interdisciplinares, realizando pesquisa com ênfase em autoria feminina, gênero e ecologia, sob o viés da ecocrítica feminista.
} 
escolas, cujas atividades resultaram na publicação do livro Corpoética: Yoga nas escolas, em 2017. Também é de sua autoria Árvores e Budas: alternativas do misticismo ecológico, lançado em 2015. Esse último trabalho está vinculado à sua tese de doutorado, defendida no Programa de Ciências Sociais da Universidade Federal da Bahia (UFBA), e é nele que indicia a reflexão acerca do misticismo ecológico, já que o cerne da sua pesquisa foram as relações entre visão de mundo, estilo de vida e atitude política desse movimento. Ecologia Mística é, pois, um desdobramento desse primeiro passo, com um olhar escrutínio do conceito em si.

Embora expresse que sua intenção não é o ineditismo e a sistematização do conceito, uma vez que ele já foi mapeado, Borges apresenta, no decorrer do trabalho, uma série de formulações que permite traçar um perfil do que ele entende por ecologia mística: "um cuidado existencial com o sentido profundo da vida" (BORGES, 2017, p. 20); o "[...] encontro entre o transcendente e o imanente, entre o noema e o noesis, entre o microcosmos e o macrocosmos, entre o ser humano e a sua casa planetária" (BORGES, 2017, p. 33); o "cuidar de si, cuidar do outro, cuidar do mundo" (BORGES, 2017, p. 47); “[é] a dança sufi, a meditação budista, os rituais xamânicos, os ritos do ayahuasca, certas formas de umbanda, a mística cristã e a teologia de um Leonardo Boff, entre tantas outras manifestações" (BORGES, 2017, p. 126), citando apenas algumas. Essa última proposição, particularmente, comprova a abertura do autor na compressão da ecologia mística. Ainda que veja o yoga como uma perspectiva indispensável para essa formulação e privilegiada para a vivência místico-ecológica, não desconsidera a experiência dos indígenas, dos afrodescendentes, dos povos de terreiro, dos daimistas e de outras vertentes do yoga.

A obra é composta por nove capítulos, e o primeiro deles, intitulado Ruminações conceituais: a expansão do presente - que pode ser considerado mais denso teoricamente -, trata, diretamente, do conceito de ecologia mística, cuja complexidade é demonstrada a partir da noção de conceito de Gilles Deleuze, o qual leva em consideração a história. Nesse âmbito, a historicidade da ecologia mística, basicamente, intersecciona Ocidente (ecologia) e Oriente (espiritualidade). O autor dialoga, ainda, com Boaventura de Sousa Santos, no sentido da crítica que esse intelectual faz à racionalidade dominante. A ecologia mística, segundo Borges, "surge como um contraponto à racionalidade instrumental", discutida por Adorno e Habermas. E, ao contradizê-la, tal ecologia concebe não apenas o imanente, mas, de igual modo, o transcendente. Ainda baseando-se em Santos, que critica a racionalidade por contrair o 
presente e expandir o futuro, sinaliza o yoga e, de modo mais amplo, a Ecologia Mística como propiciadores da dilatação do presente, a qual se materializa como a própria experiência mística, afinal, a conexão carece da presentificação.

Tendo em vista o caráter imanente/transcendente da ecologia mística, Borges legitima o tantra yoga como um campo de imanência, uma vez que o corpo tântrico se engaja no mundo, sem, contudo, deixar de transcendê-lo. Nas palavras dele, “[...] uma ecologia mística não poderia se firmar sem o apelo ao imanente: Deus é natureza; a Mãe Divina é a Mãe Terra. O sagrado se presentifica no corpo. Daí uma ecologia pautada na experiência do Ser-no-mundo" (BORGES, 2017, p. 53).

A abordagem do corpo adquire centralidade: "A Ecologia Mística consiste, portanto, em um conjunto de princípios e práticas oriundos das diversas tradições espirituais do planeta que, em síntese, entendem o corpo como a morada fundamental e o mundo como como extensão dessa morada fundamental" (BORGES, 2017, p. 54). Ao tratar do corpo, o autor argumenta que o trabalho do yoga com os chakras, i. e., os centros energéticos de consciência, é um ato ecológico. Em linhas gerais, os chakras, no corpo, comprovam a conexão entre os planos físico, emocional, energético e mental. Além disso, as posturas físicas (ásanas) alinham o yogi e a yogini à natureza. Há posturas que simulam a árvore e uma vastidão de animais.

No segundo capítulo, O pensamento místico: traduções, de forma breve, Borges reforça a integração entre corpo e meio ambiente promovida pelo yoga: durante os ásanas, os chakras são atuados, e, concomitantemente, as glândulas, a disposição mental e, por fim, a ação do/a praticante é alterada, em relação aos seres e ao mundo. Ainda nessa parte do trabalho, o autor dedica uma atenção maior ao yoga enquanto universo de estudo. Ele traça uma tipologia dos modos de acesso a essa prática milenar. Nesse sentido, há yogis - ou aspirantes - dogmáticos, utilitaristas, hermenêuticos e fenomenológicos; além de curiosos, praticantes e adeptos.

Toda essa abordagem em torno do yoga e do tantra faz de Ecologia Mística um rico material para quem busca se aprofundar não somente nessa perspectiva ecológica espiritualizada, mas no próprio yoga. Especialmente nos capítulos três, Autoanálise por uma ecologia mística na busca do Si-mesmo; seis, Os ásanas para o Yoga: significações; sete, Mestres; oito, Fragmentos de um diário: a primeira viagem à Índia; e nove, O Buddhi Yoga, há nomes de escolas (Ashtanga Vinyasa Yoga, Tantra Yoga, Raja Yoga, Hatha Yoga, Yoga Integral etc.), de mestres e instrutores (Sri Aurobindo, A Mãe, Paramahansa Yogananda, Ananda Murti, Krishnamacharya, Iyengar, De Rose, 
Pedro Kupfer, entre outros), além de um sem-número de expressões do campo semântico yogi, como: ásanas, pranayamas, sádhana, samádhi, kundalini, karma samskara e dharma. Mais do que isso, esses capítulos demonstram a relação vivencial do yogi e acadêmico com a ecologia mística, a partir de uma interação profunda e ética com o yoga.

O último capítulo, inclusive, é a síntese da trajetória de Borges pelo yoga e por outros caminhos. O seu Buddhi Yoga é a semantização do seu corpo e da sua consciência atentos e acessíveis às conexões. Ele é um yogi insone - tomando de empréstimo um adjetivo seu para caracterizar o místico -, disposto em posturas ora de equilíbrio, ora de força, ora de flexibilidade, para identificar e experienciar aquilo que se comunica com o seu misticismo ecológico. O Buddhi Yoga é o yoga místico-ecológico do autor, espiritual, transdisciplinar e multidimensional. No seu sádhana, interagem o Asthanga Vinyasa Yoga, o Tantra e a sua percepção dos chakras, a meditação Vipássana, o Hatha Yoga, o Yoga Shakti e o Vinyasa Krama. Nesse yoga versátil, o almejado samádhi é "[...] uma forma de conhecer o mundo pela identidade" (BORGES, 2017, 160). Transcendência e imanência, aí, se confundem. Os conceitos de karma e dharma também são fundamentais para uma ecologia mística - e são eles que encerram o capítulo -, já que “[...] ao praticar Yoga e libertar-se dos condicionamentos, o indivíduo enxerga a si mesmo, enxerga o seu dharma - sua posição - no mundo e, ao mesmo tempo, encarna sua missão para com o Todo" (BORGES, 2017, p. 164).

O capítulo quatro, Uma estrada essencial: a travessia acadêmica, também traz uma pessoalidade, porém, referente à formação acadêmica e às experiências do autor enquanto professor universitário. Ele próprio contra-argumenta a sua exposição: "Não faria sentido falar de Ecologia Mística se, em algum momento, eu não me aventurasse por esse caminho mais autoral" (BORGES, 2017, p. 107). E complementa: "Se é possível transcender à pessoalidade, ao 'ego', através de uma ecologia mística, deve-se fazê-lo muito bem calcado na história pessoal. Ou seja, para transcender ao ego, é preciso curá-lo" (BORGES, 2017, p. 107) Como ele também antecipa, nesse caminho profissional, o yoga e a ecologia mística estiveram sempre presentes, na ação pessoal, nas pesquisas e nos projetos. Ecologia Mística é o retrato dessa intersecção.

O capítulo cinco, Ecologia Mística: relatos, é iniciado com o registro de dois retiros espirituais dos quais o autor participou. Conforme esclarece, trata-se de uma experiência místico-ecológica que surge do entrecruzamento do acadêmico, do existencial e do espiritual. Em seguida, Borges discorre sobre a ascese, a partir de 
citações de diferentes mestres/as e yogis, concluindo que, em planos físicos e/ou sutis, a ecologia mística interage com a natureza. A ecologia tratada por ele é, explicitamente, a ambiental. Contudo, em inúmeras passagens, outras ecologias ganham expressividade e se inter-relacionam com a ecologia mística, ainda que não haja uma referência a termos específicos, com exceção da ecologia dos saberes de Boaventura de Sousa Santos e das ecologias do corpo, da alma e do espírito, de Juracy Marques. Nesse sentido, cabe expor o fragmento: "Relatos biográficos de mestres como Sivananda, Sri Aurobindo, Ananda Murti, Gopi Krishna e tantos místicos ocidentais retratam modos diferenciados de lidar com a mente, o corpo, os sentidos, a morte, o outro e o mundo" (BORGES, 2017, p. $115)$.

São interações com diversas ecologias, as quais, em conformidade com Félix Guattari (1990), poderiam ser referidas como ecologia ambiental, social e das subjetividades humanas (i. e., as três ecologias). A ecologia social, vale mencionar, pulsa no discurso crítico do, também, cientista social, quando, por exemplo, ele aborda as ruas pobres da Índia e do Brasil, bem como o utilitarismo do yoga e o acesso elitista a essa prática, no Ocidente. Essa dimensão está na própria preocupação com o coletivo, nutrida pelo yoga. Quanto à ecologia das subjetividades humanas, Borges pode servir de modelo, na medida em que revela os seus "territórios existenciais de subjetividade" (inclusive, em fragmentos de poesia), para usar um conceito de Guattari.

São muitos os conceitos de ecologia mística dissolvidos nos capítulos, impregnados de subjetividade, mas a escolha metodológica do autor, claramente exposta, legitima isso. Uma delas, em especial, parece conveniente para o fechamento deste escrito, por sua beleza e utopia:

O simbolismo da Ecologia Mística não seria mais encabeçada pelo OM, ou por árvores, ou por uma pessoa sentada em posição de lótus, mas, sim, por uma mandala feita de pessoas em meio a um arvoredo: seus pés juntos se voltam para o centro de um círculo formado por seus corpos deitados no chão, em reverência ao céu e à terra" (BORGES, 2017, p. 128).

A imagem poética foi lançada. Resta corporificá-la.

\section{Referências}

BORGES, João José. Ecologia Mística. Juazeiro-BA: SABEH, 2017. 
GUATTARI, Félix. As três ecologias. Tradução Maria Cristina F. Bittencourt. Campinas-SP: Papirus, 1990. 